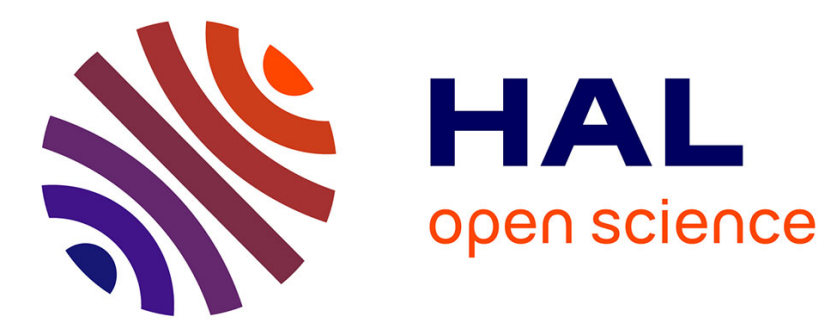

\title{
The Fuzziness of Travel-to-Work Areas
}

Zhiqiang Feng

\section{To cite this version:}

Zhiqiang Feng. The Fuzziness of Travel-to-Work Areas. Regional Studies, 2009, 43 (05), pp.707-720. 10.1080/00343400801922806 . hal-00516195

\section{HAL Id: hal-00516195 \\ https://hal.science/hal-00516195}

Submitted on 9 Sep 2010

HAL is a multi-disciplinary open access archive for the deposit and dissemination of scientific research documents, whether they are published or not. The documents may come from teaching and research institutions in France or abroad, or from public or private research centers.
L'archive ouverte pluridisciplinaire HAL, est destinée au dépôt et à la diffusion de documents scientifiques de niveau recherche, publiés ou non, émanant des établissements d'enseignement et de recherche français ou étrangers, des laboratoires publics ou privés. 


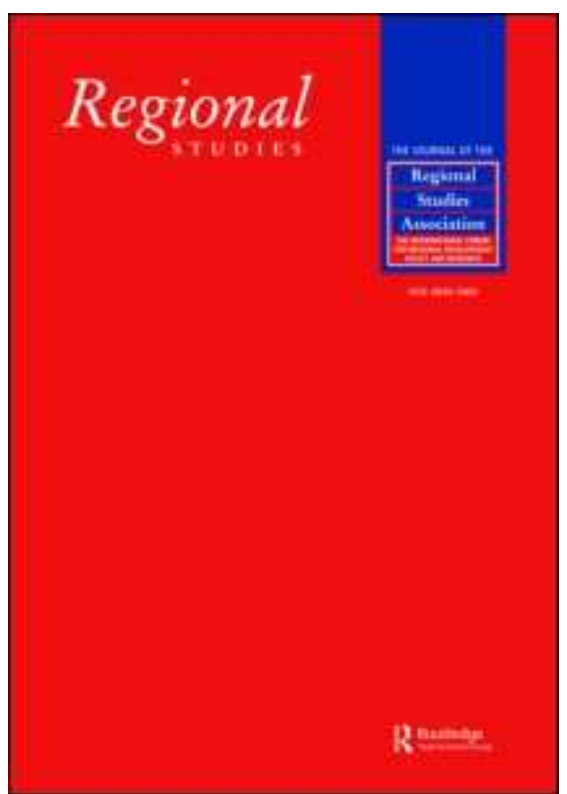

The Fuzziness of Travel-to-Work Areas

\begin{tabular}{|r|l|}
\hline Journal: & Regional Studies \\
\hline Manuscript ID: & CRES-2006-0038.R2 \\
\hline Manuscript Type: & Main Section \\
\hline JEL codes: & $\begin{array}{l}\text { R0 - General < R - Urban, Rural, and Regional Economics, R12 - } \\
\text { General Regional Economics < R - Urban, Rural, and Regional } \\
\text { Economics }\end{array}$ \\
\hline Keywords: & Travel to Work Areas, Fuzzy set theory, Representation, England \\
\hline
\end{tabular}

\section{SCHOLARONE" \\ Manuscripts}




\section{Fuzziness of Travel-to-Work Areas}

Journal: Regional Studies

Manuscript ID: CRES-2006-0038.R2

JEL codes:

R0 - General \&lt; R - Urban, Rural, and Regional Economics, R12 -

Size and Spatial Distributions of Regional Economic Activity \&lt; R1

- General Regional Economics \&lt; R - Urban, Rural, and Regional Economics

Keywords: Travel to Work Areas, Fuzzy set theory, England, Representation

\section{Zhiqiang Feng}

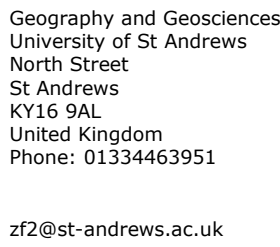




\title{
The Fuzziness of Travel-to-Work Areas
}

\author{
ABSTRACT \\ Keywords: Travel-to-Work Areas, Fuzzy set theory, Representation, England \\ Travel-to-Work Areas (TTWAs) have been used widely by governmental agencies and \\ academic institutions. However, they have been criticised because the boundaries \\ separating TTWAs are imperfect in the sense that there are always commuting trips \\ crossing them. This paper aims to investigate the fuzziness of Travel-to-Work Areas by \\ applying fuzzy set theory. The methodology of defining fuzzy Travel-to-Work Areas is \\ described. Indicators measuring size and overlap of fuzzy TTWAs are suggested. The \\ cartographic representation of fuzzy TTWAs is discussed. In the last section, the \\ advantages of fuzzy TTWAs and some potential applications are proposed. \\ CRES-2006-0038.R2 \\ Flou en matière de zones d'emploi \\ Zhiqiang Feng \\ Codes JEL : \\ R0 - General \&lt; R - Economie urbaine, rurale et régionale, R12 - \\ Taille et répartition spatiale des activités économiques régionales \&lt; R1 \\ - Economie régionale générale \&lt; $\mathrm{R}$ - Economie urbaine, rurale et régionale \\ Mot-clé : zones d'emploi, théorie des ensembles flous, Angleterre, représentation \\ $\underline{\text { Flou en matière de zones d'emploi }}$
}




\title{
RESUME
}

Les zones d'emploi (TTWA) ont été largement utilisées par les agences gouvernementales et les institutions universitaires. En revanche, elles ont été critiquées du fait que les limites qui séparent ces zones sont imparfaites en ce sens qu'elles sont toujours traversées par des liaisons domicile-travail. L'objet de cet article est d'analyser le flou des zones d'emploi en appliquant la théorie des ensembles flous. Il décrit la méthodologie utilisée pour définir les zones d'emploi floues et suggère des indicateurs pour mesurer la taille et le chevauchement de ces zones. Les auteurs débattent de la représentation cartographique des zones d'emploi floues. Dans la dernière section, ils présentent les avantages des zones d'emploi floues et quelques applications potentielles.

CRES-2006-0038.R2

Fuzziness of Travel-to-Work Areas

Zhiqiang Feng

JEL codes:

R0 - General \&lt; R - Urban, Rural, and Regional Economics, R12 Size and Spatial Distributions of Regional Economic Activity \&lt; R1 - General Regional Economics \&lt; R - Urban, Rural, and Regional Economics

Keywords:

Arbeitsmarktregionen

Fuzzymengen-Theorie

England

Darstellung

\section{Die Unschärfe von Arbeitsmarktregionen}

\begin{abstract}
Arbeitsmarktregionen werden von Regierungsbehörden und akademischen Institutionen in großem Umfang genutzt. Diese Methode ist jedoch kritisiert worden, weil die Grenzen zur Trennung von Arbeitsmarktregionen insofern Mängel aufweisen, als dass stets auch Pendler diese Grenzen überschreiten. In diesem Beitrag wird die Unschärfe der Arbeitsmarktregionen durch Anwendung der Fuzzymengen-Theorie untersucht. Die Methodologie zur Definition
\end{abstract}


unscharfer Arbeitsmarktregionen wird beschrieben. Es werden Indikatoren zur Messung der Größe und Überlappung von unscharfen Arbeitsmarktregionen vorgeschlagen. Die kartografische Darstellung unscharfer Arbeitsmarktregionen wird erörtert. Im letzten Abschnitt werden die Vorteile unscharfer Arbeitsmarktregionen behandelt und einige potenzielle Anwendungen vorgeschlagen.

\title{
CRES-2006-0038.R2
}

Ambigüedad de las cuencas de empleo Zhiqiang Feng

\begin{abstract}
Las cuencas de empleo han sido utilizadas con profusión por agencias gubernamentales e instituciones académicas. Sin embargo, se ha criticado que las fronteras que separan estas cuencas de empleo son imperfectas porque siempre hay viajantes que las cruzan. En este artículo investigamos la ambigüedad de las cuencas de empleo aplicando la teoría de conjuntos difusos. Describimos la metodología para definir las cuencas de empleo difusas. Sugerimos indicadores para medir el tamaño y el solapamiento de las cuencas de empleo difusas. También analizamos una representación cartográfica de las cuencas de empleo difusas. En la última sección, proponemos las ventajas de las cuencas de empleo difusas y algunas posibles aplicaciones.
\end{abstract}

Keywords:

Cuencas de empleo

Teoría de conjuntos difusos

Inglaterra

Representación

R0 - General \&lt; R - Urban, Rural, and Regional Economics, R12 -

Size and Spatial Distributions of Regional Economic Activity \&lt; R1

- General Regional Economics \&lt; R - Urban, Rural, and Regional Economics 


\section{The Fuzziness of Travel-to-Work Areas}

\section{INTRODUCTION}

Labour market areas, conceptually, identify the areas within which there is a close relationship between labour supply and demand. Conventionally, administrative areas are often used as a surrogate for local labour market areas (LLMAs) for statistical, analytical and policy-making purposes. However, this practice has long been criticised because administrative areas seldom partition the territory in a way that reflects functional reality (SMART, 1974; BALL, 1980). Labour market policies targeting administratively defined areas may be less effective than policies targeting functionally delimited regions (COOMBES et al., 1986). In addition, comparison of labour market statistics across administrative areas may not be so meaningful because they do not reflect labour markets (COOMBES, 2002). As a consequence, there has been a call to define labour market areas in a consistent and formal way for statistical purposes (COOMBES et al., 1986; CATTAN, 2001).

In the UK the practice of defining local labour market areas can be traced back to the 1950s (BALL 1980; COOMBES and OPENSHAW, 1982). Initially influenced by the American concept of metropolitan areas, proponents argued that journey to work behaviour was the most appropriate indicator of local labour market areas (GERARD, 1958; VANCE, 1960). The method implemented was to aggregate local authority areas subject to close journey to work relationship between these areas. SMART (1974) was perhaps the first to systematically formalise the procedure of Travel-to-Work Area 
(TTWA) construction. In the 1980s the algorithm developed by COOMBES et al (1986) was accepted by the Department of Employment, to produce Travel-to-Work Areas across the UK based on 1981 census data. The TTWA system was later updated based on the 1991 census.

The methodology developed by COOMBES et al. (1986) has since been adopted by many countries, including Italy (SFORIZO et al, 1997), Spain (CASADO-DIAZ, 2000), New Zealand (PAPPS and NEWELL, 2002), Denmark (ANDERSON, 2002), and Australia (WATTS, 2004). The methodology was generalised and recommended by EUROSTAT (1992, cited in COOMBES, 2000) as a standard program to construct local labour market areas. It has been recognised that different sub-groups may have different commuting radii and thus different TTWAs (GREEN 1997). CASADO-DIAZ (2000) constructed TTWAs by gender, industry and occupation and found industry-specific areas presented high degree of variations. For example, there were a large number of areas for agriculture but a small number of areas for manufacturing and construction. NEWELL and PERRY (2003) defined 2001 labour catchments based on both 1991 and 2001 spatial units and assessed the stability of labour catchments between 1991 and 2001. They found that there was a reduction of number of labour market areas due to the increase in commuting distances but changes tended to preserve the broad structure of labour market areas identified in 1991.

As an alternative geography (GREEN, 1997) and an approximation of LLMAs, TTWAs have been used to calculate unemployment rates, identify assisted areas for industrial policies, investigate job search behaviour, and re-organise local government (WATTS, 
2004; NEWELL and PERRY, 2003). In addition, these areas have been used for evaluation of economic efficiency, job opportunities and regional disparities. Travel-toWork Areas have also been used for migration study. PAPPS and NEWELL (2002) pointed out that Travel-to-Work Areas are useful in distinguishing employment related and non-employment related migration and they have used these areas to estimate the average distance of moves within which migration can be assumed to be non-work related.

The derivation of mutually exclusive TTWAs has been questioned in four inter-related aspects (HASLUCK, 1983; WEBSTER, 1997; NEWELL and PERRY, 2003). First, the boundaries separating the TTWAs may not be as significant as they are presented, because some commuters cross the boundaries, which creates interdependence between adjacent areas. Secondly, researchers often combine adjacent TTWAs to overcome the problem of boundary crossing, but this usually creates a new problem in that the defined TTWA becomes too large for daily journey-to-work activities. Consequently, it may manifest weak internal cohesiveness and integration between the component areas. Thirdly, the unemployment rate on TTWAs can conceal geographical pockets of high and low unemployment, so that the areas are not homogeneous with regard to labour force statistics. Finally, boundaries of TTWAs may demonstrate a lack of continuity over time due to investments in housing and transport, as well as the prevailing local economic conditions (WATTS, 2004).

The indeterminate nature of the boundary of TTWAs is not unique. It has been argued that apart from a few man-made geographical regions such as political areas, or parks, it 
is almost impossible to draw a clear line around geographical regions (ROLLAND-MAY, 1984; COUCLELIS, 1996). GALE (1976) proposed that the ambiguity inherent in assigning locations to regional classes be acknowledged formally and he applied the notion of a three-value fuzzy subset to conceptualise a region.

PLANE (1981) was among the first who suggested that urban systems are interlinked and should be treated as overlapping rather than mutually exclusive. He found that as high as one third of total flows crossed the borders of the urban fields defined by BERRY and GILLARD (1978) when he used commuting flow data at a finer scale. He argued that a single geographical point can belong to more than one daily urban system (PLANE, 1981) and the mutually exclusive view of urban fields does not reflect the reality.

In France, the French Institute of Statistics defines urban and rural areas for statistical purposes. Journey to work is an important criterion in delimiting boundaries of urban areas. In the classification, urban poles are defined as urban units with a minimum of 5000 jobs, which are not in the suburban ring of another urban pole. An urban area is defined by amalgamating municipalities where there are at least 40 percent of workers traveling to a specific urban pole. Municipalities where less than 40 percent of the residential population work in one urban area are defined as multipolarised municipalities (LE JEANNIC, 1997). In this way municipalities which belong to different urban areas are explicitly grouped together forming a distinct category. The difficulty of assigning these municipalities to any individual urban area is therefore avoided. 
Fuzzy set theory developed by ZADEH (1965) is useful in definition and analysis of fuzzy regions. In fuzzy set theory, an element can simultaneously belong to different sets to different degrees whilst in classical set theory an element can only belong to one and only one set. Applying fuzzy set theory to regionalisation allows the definition of fuzzy regions where any of the constituent spatial units may belong to more than one region.

There have been a handful of studies in fuzzy regionalization. For example, fuzzy clustering, an extension to conventional clustering, has been used in the definition of socio-economic regions (HARRIS et al, 1993), urban areas (HEIKKILA et al., 2003), and geodemographic regions (FENG and FLOWERDEW, 1998; HATZICHRISTOS, 2004). Fuzzy regionalization related to flow data has drawn less attention. PLANE (1998) applied fuzzy set theory to migration regions in the US. He treated factor loadings as fuzzy information measure, indicating the degree to which a state belonged to a migration region. Fuzzy entropy, fuzzy count and overlap index (see below) were used to characterize fuzzy migration regions. Fuzzy measures were employed to examine congruence between in-migration regions and out-migration regions, and persistence of migration regions over time.

In this paper the fuzziness of Travel-to-Work Areas is examined and analysed. The next two sections respectively describe Special Workplace Statistics (SWS) which provide journey to work data and the methodology of construction of conventional TTWAs. The fourth section presents how to define fuzzy memberships for Travel-to-Work Areas. The fifth section proposes measures for size of fuzzy TTWAs and overlap between fuzzy TTWAs. The sixth section deals with the cartographic representation of fuzzy TTWAs. 
To conclude, the final section discusses the advantages of fuzzy measures and proposes some potential applications.

\section{SPECIAL WORKPLACE STATISTICS}

Special Workplace Statistics (SWS) are statistics on journeys-to-work of people who are in employment. The census of population in UK derived commuting flows and journey to work distances on the basis of information on place of residence and on place of work. Individuals are requested to provide a detailed address for the residence and workplace, preferably including a full unit postcode from which the geographical location can be identified. The 1981 and 1991 Special Workplace Statistics (SWS) are drawn from the 10\% sample data while the 2001 SWS are 100 percent data (COLE et al, 2002).

There are three sets of commuting data in the 1991 SWS. Set A and Set B provided a set of statistics for employed or self-employed population by residence and workplace respectively. They are not flow data matrices. Set $\mathrm{C}$ contained the journey to work counts between wards in England and Wales and between postcode sectors in Scotland. SWS Set C is the data set that involves commuting flow data. The 1991 SWS Set C for England, with a full size of 8619 by 8619 wards, is used in this study.

For each origin-destination cell in 1991 SWS Set C, there are 274 counts available. They cover topics such as the mode of transport to work, social class, socio-economic group, occupations, cars available to household, hours worked, distance travelled, family position, industrial division and age structure of males and females aged over 16 in employment. 
It was usually assumed that commuting was on a daily basis since no question was asked on when journeys to work took place or whether they varied on different days of the week. However, some commuters may choose weekly commuting because their main residence was too far from their workplace. These weekly commuters might be identified approximately by the long distance that they travelled. The weekly commuting trips should be omitted for TTWA construction as local labour markets are based on daily commuting patterns. GREEN et al (1999) identified workplace destinations which are beyond feasible daily commuting range by 1991 counties. With reference to their list of counties a threshold of 200 kilometres between ward centroids is chosen to eliminate non-daily commuting flows in SWS Set C. A total of 63480 commuters were thus removed from the dataset, accounting for 0.4 percent of total commuters.

\section{CONSTRUCTION OF TRAVEL-TO-WORK AREAS}

The basic principle for defining local labour markets is to generate regions in a way that commuting flows between them are minimised and commuting flows within them are maximised. Also it is preferable to have the maximum possible number of TTWAs, subject to constraints of minimum resident population and minimum demand-side and supply-side self-containment. A target threshold is set at 75 percent self-containment when the working population is under 20,000 , and at 70 percent self-containment when the working population is over 20,000. A TTWA must also have a minimum of 3,500 working population. In the 1991 census SWS were released at the ward level and the district level. Therefore, the smaller census wards are used as basic spatial units to define TTWAs (COOMBES et al., 1986; ONS and COOMBES, 1998). 
A multi-stage aggregation algorithm is developed for construction of TTWAs (COOMBES, et al., 1986). The first stage detects wards which might form part of a local labour market area focus. Two criteria, job ratio and the self-containment measure, are implemented for they stand for the two extremes of candidacy for being the focus of a local labour market. The job ratio distinguishes wards which are centres of incommuting, whilst the self-containment measure finds wards that have very little outcommuting (COOMBES et al., 1986).

Many foci identified in stage one are inter-linked and should be amalgamated. Therefore, the second stage searches those foci which have strong commuting links between them to form focus areas. A linkage index was used to assess the strength of the commuting link. Each of the foci from stage one is ordered by commuting inflows. Then each is considered in turn. A focus will be considered for merging if the minimum value of the measures of self-containment by residence and employment is less than a certain threshold. Also, there must be other foci from which at least 10 percent of commuters travel to the target focus and to which at least 1 percent of commuters from the target focus are destined.

In the third stage, all areas are considered, including the foci and the non-foci. The foci are assessed according to an objective function (COOMBES et al, 1986). Therefore, all foci that fail to meet an initial minimum value are, in turn, joined with those areas that rank highest according to the linkage index. Again, the algorithm will repeat this process 
with any merged focus, joining it with other areas until it satisfies the constraint. The areas generated from this stage are termed proto Travel-to-Work Areas.

In the fourth stage, those wards which have so far remained unattached are attached to the proto Travel-to-Work Area based on the linkage index. The wards are considered in descending order of the number of residents in the ward. Wards are assigned to the proto Travel-to-Work Areas to which they have the strongest commuting link.

The last stage involves splitting proto Travel-to-Work Areas which do not qualify as a Travel-to-Work Area. A proto travel-to-work area is split if it fails to meet the threshold for an independent area and has its component wards reallocated to the remaining area with which it had the closest commuting links. This stage continues until all remaining areas qualify as Travel-to-Work Areas.

The 1991 TTWAs were developed on 1991 wards based on the above algorithm. The 1998 electoral wards were best fitted into these travel areas. A consultation with local governments was conducted to modify the boundaries reflecting local knowledge. TTWAs were defined separately for England, Wales, Scotland and Northern Ireland. There are 207 Travel-to-Work Areas for England (ONS and COOMBES, 1998).

TTWAs have been used in academia and local governments over many years (HATTERSLEY and CREESER, 1995). A popular example is the use of TTWAs for the analysis of local unemployment patterns (ADAMS et al., 2000; ADAMS et al., 2001; GRIPAIOS and WISEMAN, 1999). Another example is to examine local trends in 
employment structure (O'DONOGHUE, 2000). TTWAs have also been used in analysis of commuting patterns (ATKINS et al, 1996; MCQUAID and GREIG, 2001). Some studies choose TTWAs as their geography because other geographies used have failed to reveal the influences operating at the local labour market level (FIELDHOUSE and GOULD 1998; WARD and DALE, 1992).

\section{FUZZIFICATION OF TRAVEL-TO-WORK AREAS}

The key step in fuzzification is to define a membership function so each element may be allocated to the fuzzy set to a certain degree. In our case, we need to design a membership function so that every ward can be assigned a membership value in each of the TTWAs. Fuzziness can be disclosed and investigated after the membership function is designated.

Travel-to-work phenomena have two closely related aspects when a TTWA is used as a spatial reference. One aspect is that workers who live in a constituent ward of the TTWA travel from the area to work in a ward. The TTWA is treated as a residential place which supplies labour. The other aspect is that workers who live in a ward travel to work in the constituent ward within the TTWA. The TTWA is then regarded as a workplace, as a demand side of labour market. Hereafter the first type of region is named a fuzzy residential area and the second type of region a fuzzy workplace area. A fuzzy TTWA can be constructed by combining these two aspects together.

With reference to the fuzzy residential area, the membership function of ward $i$ is defined as: 
$M_{i t}^{\prime}=\sum_{k \in t} c_{k i} / \sum_{j \in T} c_{j i}$

where $c_{k i}$ refers to the number of commuters to ward $i$ from ward $k$ in area $t$, and $c_{j i}$ refers to the number of commuters to ward $i$ from ward $j$ in area $T$. While $t$ refers to one certain TTWA, $T$ refers to the full set of TTWAs. Therefore, the membership value of ward $i$ belonging to TTWA $t$ as a fuzzy residential area is defined as the proportion of the total number of commuters who originate from area $t$ to the total number of commuters originating from all wards including ward $i$ itself. If there are no commuters travelling from area $t$ to ward $i$ then the membership of ward $i$ in TTWA $t$ as a fuzzy residential area is zero. If all commuters travelling to ward $i$ come from wards in TTWA $t$ then the membership of ward $i$ in area $t$ as a fuzzy residential area is one.

With reference to the fuzzy workplace area, the membership function of ward $i$ is defined as: $M_{i t}^{\prime \prime}=\sum_{k \in t} c_{i k} / \sum_{j \in T} c_{i j}$ where $c_{i k}$ refers to the number of commuters from ward $i$ to ward $k$ in area $t, c_{i j}$ refers to the number of commuters from ward $i$ to ward $j$ in area $T$, and $t$ and $T$ are the same parameters when fuzzy residential areas are defined. Therefore, the membership of ward $i$ belonging to TTWA $t$ as a fuzzy workplace area is defined as the proportion of the total number of commuters from ward $i$ who travel to work in area $t$ to the total number of commuters originating from ward $i$. If there are no commuters from ward $i$ to area $t$ then the membership of ward $i$ in area $t$ as a fuzzy workplace area is zero. If all commuters 
originating from ward $i$ end up working inside TTWA $t$ then the membership of ward $i$ in area $t$ is one. The memberships of a ward in a TTWA as the fuzzy residential area and the fuzzy workplace area are respectively equivalent to TTWA specific in-commuting and out-commuting rates but in a real number format between 0 and 1 .

By combining the two membership functions, the membership function of ward $i$ in fuzzy TTWA $t$ can be defined as:

$M_{i t}=\left(M_{i t}^{\prime}+M_{i t}^{\prime \prime}\right) / 2$

Therefore the membership of ward $i$ in fuzzy TTWA $t$ is the average of membership of ward $i$ in area $t$ as a fuzzy residential area and membership of ward $i$ in area $t$ as a fuzzy workplace area. If there are neither commuters travelling to ward $i$ from area $t$ nor commuters originating from ward $i$ to area $t$ then the membership of ward $i$ in fuzzy TTWA $t$ is zero, indicating that ward $i$ does not belong to TTWA $t$ at all. If all commuters travelling to ward $i$ come from wards in area $t$ and at the same time all commuters originating from ward $i$ work in wards inside area $t$ the membership of ward $i$ in fuzzy TTWA $t$ is one, meaning that ward $i$ fully belongs to the TTWA. In addition, memberships for a ward to each of all TTWAs will sum up to unity because only commuters who work in England are taken into consideration.

From the membership function and the construction criteria of conventional TTWAs it can be expected that usually a ward has the largest membership value in the travel area to which it is allocated no matter whether the TTWA is treated as a fuzzy residential area, a fuzzy workplace area or a fuzzy TTWA. 
Figure 1 presents a map of memberships of wards in the TTWAs to which they were allocated in London and the surrounding areas. The darker the colour the higher the membership values in the areas. It can be seen that usually TTWAs have a cluster of high membership values in the central areas, which is the job focus of the TTWAs. From the centre of TTWAs to the border areas the membership values decrease. In the whole of England, 246 wards have a membership below 0.5 in the TTWA to which they are allocated, accounting for 2.8 percent of the total. Among them 240 wards are located in the border areas. Only six wards out of 5702 wards in non-border areas have a membership below 0.5 . Summary statistics show that the average membership of wards in the border areas of the TTWAs is 0.69 while the average for wards in other parts of TTWAs is 0.85 . Therefore the wards in the border areas between TTWAs form a transitional zone where some people cross the border working in the TTWA on the other side.

Insert Figure 1 here

Twenty TTWAs which contain the highest proportion of constituent wards with a membership below 0.5 are listed in Table 1 . Keswick is a small TTWA, located in the Lake District. Out of four constituent wards two of them have a membership below 0.5 in Keswick. Keswick is quite special in that most local people are involved in the tourist industry and work locally. However, a fair proportion of people still travel to other areas for employment. The last three TTWAs contain 12.5 percent of wards with a low membership value. The percentage is not particularly high in comparison with the average proportion for all TTWAs. It can be argued that TTWAs consisting of a high 
proportion of wards with a low membership in the TTWA are not well defined because their self-containment ratio is low. The construction of conventional TTWAs is quite successful in this regard because there are not many TTWAs comprising a high proportion of wards with low memberships associated with them.

Insert Table 1 here

In theory a constituent ward should have a higher membership in its associated TTWA than in any other TTWA. In reality some wards may have similar memberships in different TTWAs. If the difference between two memberships of a ward in two TTWAs is less than 0.1 then the ward can be regarded as having similar memberships. There are 103 wards which have similar memberships in two TTWAs. For example, New Mills North ward, which is located in Buxton TTWA at a membership of 0.52 , has a membership of 0.43 in Manchester. Another example, Ingleton ward which is at the border areas of three TTWAs was assigned to Barnard Castle with a membership of 0.20. Nevertheless Ingleton has a membership of 0.29 in Darlington and a membership of 0.24 in Bishop Auckland. There is definitely ambiguity in allocating New Mills North to either Manchester or Buxton. It is even more difficult to link Ingleton to any of the three TTWAs. This is because similar proportions of people in New Mills North or Ingleton travel to two or three TTWAs for working and similar proportions of people come in from those areas. TTWAs have drawn some criticism from local authorities. Partially it is because the TTWA boundary does not always reflect the ground truth. In some places such as Ingleton the reality defies any attempt to draw a clear-cut boundary of TTWAs.

\section{THE SIZE AND OVERLAP OF TRAVEL-TO-WORK AREAS}


One way to measure the size of a fuzzy region is to use the set-theoretic concept of count (PLANE, 1998). In the classical set concept, the membership is one, indicating that a zone belongs to a TTWA, or zero, indicating otherwise. Therefore, counting the number of wards included in a TTWA is equivalent to.adding up memberships of all wards in it. By extension the rule can also be applied to the fuzzy TTWAs. The count of a fuzzy TTWA can be defined as the sum of memberships of all wards in the fuzzy TTWA. It can be regarded as the number of whole-ward equivalents contained in a fuzzy TTWA.

Table 2 lists the top 20 fuzzy TTWAs in terms of fuzzy count. The conventional count of wards is also presented in the table. The largest 11 TTWAs keep their positions as ranked according to conventional counts. This shows that the largest TTWAs generally have the largest fuzzy counts as well. Norwich, ranked $14^{\text {th }}$ in terms of the count of wards, moves up two positions to $12^{\text {th }}$ while Guildford and Aldershot goes down one position. Bristol and Nottingham share the same conventional count but are differentiated in fuzzy count with Bristol having the larger fuzzy count. Fuzzy count gives a more precise measure in terms of the range of coverage of fuzzy TTWAs. In addition, that a TTWA has a larger fuzzy count than conventional count indicates that a number of wards outside the TTWA have strong connections with it and the conventional count fails to capture the journey to work connection from outside the TTWA. In contrast, that a TTWA presents a lower fuzzy count than conventional count means that its size is smaller than measured by conventional count because some wards in the TTWA have relatively strong connections with other TTWAs rather than with the TTWA itself. 
Inset Table 2 here

Size can also be defined using working population. We can define the population size as the sum of membership values of each ward in the fuzzy TTWA as a fuzzy workplace area multiplied by the working population who live in the ward. The result is the total number of people who work in the fuzzy TTWA. Table 3 shows the top 20 fuzzy TTWAs in terms of working population. London is the largest one with a working population of nearly 3 million. The second one is Manchester with a working population of 773 thousand. Crawley ranked $20^{\text {th }}$ with a working population of 177 thousand.

Insert Table 3 here

Size can further be defined using the land area that a fuzzy TTWA covers. Similar to the definition of working population size, the area size may be defined as the sum of membership values of each ward in the fuzzy TTWA multiplied by the area of the ward. The assumption behind this definition is that population is distributed evenly within each ward and therefore the membership of the ward in a TTWA also represents the proportion of total area that can be allocated to the TTWA. Table 4 lists the top 20 TTWAs with the largest area in square kilometres. London is again the largest one with an area of 4.7 thousand square kilometres. Birmingham comes second with 1.77 thousand square kilometres. The third one is Manchester with 1.75 thousand kilometres. Harrogate and Ripon ranked $20^{\text {th }}$ with an area of 1.15 thousand square kilometres. In comparison with conventional area, that a TTWA has a larger fuzzy area than conventional area indicates that a number of wards outside the TTWA have strong connections with it and the area they cover outweighs the area lost due to the wards inside the TTWA having connections 
with other TTWAs. In contrast, that a TTWA presents a lower fuzzy area than conventional area means that the size of the TTWA is smaller than measured by conventional area because some of the wards in the TTWA have relatively strong connections with other TTWAs rather than with the TTWA itself.

Insert Table 4 here

If the wards can be collapsed into parts proportional to the membership values in each fuzzy TTWA and re-amalgamated in a way that they join only with other parts of any ward that belong to the same TTWA then the whole geographical space is re-partitioned into the same number of TTWAs with all constituent units in a TTWA fully belonging to it. Therefore, the fuzzy area of a fuzzy TTWA can be regarded as the area it covers when the 100 percent self-containment criterion is satisfied. Three types of size for fuzzy TTWAs reflect different dimensions of TTWAs. Apart from size by working population, which is the same as the conventional measure, the fuzzy count and fuzzy area are more accurate indicators than conventional counterparts.

Size of fuzzy TTWA can be defined using a single formula:

$$
S_{t}=\sum_{i} M_{i t} * Q_{i}
$$

If $Q_{i}$ is unity, then the fuzzy size $S_{t}$ is the fuzzy count. If $Q_{i}$ is number of commuters and $M_{i t}$ is set at membership in TTWA $t$ as workplace then $S_{t}$ is the size by working population. If $Q_{i}$ refers to land area then $S_{t}$ is the size by land area. 
One of the principal differences between bivalent and fuzzy regions is that fuzzy regions overlap one another. Fuzzy set theory offers some useful measures to examine the extent of overlap. The intersection set of two fuzzy sets, A and B, consists of elements by taking the smaller of the memberships in set A and set B. In contrast, the union set of two fuzzy sets, $\mathrm{A}$ and $\mathrm{B}$, consists of elements by taking the larger of the memberships in set $\mathrm{A}$ and set B. Two measures of the amount of overlap of fuzzy regions are suggested by PLANE (1998). Unlike overlap between fuzzy migration regions where the overlap appears for all pairs of regions no matter how far they are separated, the overlap between Travel-toWork Areas only occurs when they are within commuting distances, particularly between areas which are contiguous.

The first overlap measure is defined as the absolute count of the intersection set between TTWAs A and B:

$$
O I_{A B}=\sum_{\substack{i \in A \\ j \in B}}\left\{\min \left(M_{i A}, M_{i B}\right)+\min \left(M_{j A}, M_{j B}\right)\right\}
$$

This can be treated as the number of ward-equivalents in either area A or B which belong to both TTWAs. The second measure is defined as the ratio of the intersection of TTWA A and TTWA B to the union of the two areas, which provides a relative figure indicating the amount of overlap:

$$
O I_{A B}^{\prime}=O I_{A B} / \sum_{\substack{i \in A \\ j \in B}}\left\{\max \left(M_{i A}, M_{i B}\right)+\max \left(M_{j A}, M_{j B}\right)\right\}
$$


The relative overlap index varies from 0 to 1 . When relative index is 0 , it indicates that there are no flows between two areas and thus there is no overlap. When relative index is 1, it indicates that all wards equally belong to both TTWAs at a membership value of 0.5 , thus two areas overlap perfectly and should be merged together.

Table 5 presents the top 20 pairs of TTWAs which share the largest amount of absolute overlap. London ranks first, when paired with Slough and Woking which is located to the west of London. About 67 ward-equivalents, out of total 1140 wards, in the two TTWAs utilise the whole area as catchment areas. In fact, London and its 10 out of 11 neighbouring areas are in the top 20 positions, which demonstrates that they overlap each other to the largest extent in England. Slough and Woking also have a high overlap with three of its neighbours, Reading, Guildford and Aldershot, and Aylesbury and Wycombe. In addition, Birmingham shares a high level of overlap with two of its neighbours, Wolverhampton and Walsall, and Dudley and Sandwell. Tyneside, when paired with Sunderland and Durham, ranks sixth in the absolute overlap index.

Insert Table 5 here

Table 6 lists the top 20 pairs of TTWAs which share the largest amount of relative overlap. The pair of Bournemouth and Poole ranks first in the relative overlap index. This means that a large proportion of their Travel-to-Work Areas overlap each other after taking their fuzzy size into account. London, although it has the largest absolute overlap index with its surrounding areas, does not have a very high relative overlap index with them due to London's sheer size. Most TTWAs with high relative overlap are smaller areas, less than the average size of 41 wards. Sunderland and Durham, paired with 


\begin{abstract}
Tyneside is the only pair appearing in the top 20 in both absolute and relative overlap index.

Insert Table 6 here
\end{abstract}

\title{
CARTOGRAPHIC REPRESENTATION OF FUZZY TTWAS
}

Cartographic representation of fuzzy regions can be challenging. Conventional TTWAs can be easily represented using a solid line indicating the crisp boundary between TTWAs. Each constituent ward falls into the TTWA that it belongs to. One advantage of construction of fuzzy regions is that membership values for each constituent zone can be mapped so as to display the gradual variation of individual fuzzy regions.

Figure 2 (a-c), show memberships of wards in London separately as a residential, workplace and travel to work area. In general, as expected, there is a wide spread of wards which have some degree of connection with London in its surrounding areas. All wards located inside the first order contiguous TTWAs with London appear to have connections with London. The proportion of wards reduces when the second order contiguous TTWAs with London are examined. Only a small proportion of wards in third order or even fourth order contiguous TTWAs have meaningful linkage with London. The exceptions are Basingstoke, Reading in the west and Milton Keynes in the northwest which are third order contiguous TTWAs but have a significant proportion of wards connecting to London. London as a fuzzy residential area seems to be more compact than London as a fuzzy workplace area. This shows that reverse commuting from London 
does occur but is quite weak compared to commuting to London. A good number of journeys occur from far away wards in surrounding areas. This is in accordance with the findings that on average people travel to work in London over longer distances.

\section{Insert Figure 2 here}

The advantage of mapping memberships to a particular TTWA is to visually inspect how this fuzzy area is distributed geographically. Choropleth and dot density mapping have been used for this purpose (PLANE, 1998). The disadvantage of this method is that each map can usually represent only one fuzzy region. If there are a large number of fuzzy regions usually a number of maps are needed to show fuzzy regions.

Feng and Flowerdew (1998) used proportional symbols to represent the membership degrees in different demographic areas simultaneously. Each sector distinguished by its colour represents a membership value in a certain fuzzy area. Therefore just one map will be enough to show the distribution of all fuzzy regions. However, this method is not appropriate for a large number of fuzzy regions because there would be too many sectors in the circle which would be difficult to use colour or texture to represent.

Here an innovative method is proposed to represent the fuzzy regions. The boundary line segments will be drawn inversely proportional to the amount of overlap between the contiguous fuzzy TTWAs. If the overlap index is larger the boundary line between areas will be thinner and lighter. Otherwise the line will be thicker and darker. Firstly the overlap index between all pairs of contiguous fuzzy TTWAs is calculated. The polygon coverage of TTWAs is converted into a line coverage using GIS tools. The left polygon 
identifier and the right polygon identifier are combined to form one unique identifier for each line segment. Then each line segment can be joined with the overlap index which also has the combined left polygon and right polygon identifier.

Figure 3 shows the absolute overlap index for TTWAs. The nature of fuzziness for TTWAs is very well displayed on the map. Different from a traditional map where a uniform solid line represents the crisp boundary between regions, the boundary for fuzzy TTWAs illustrates which TTWAs tend to overlap with neighbouring areas. For example, it is clear that London overlaps to a greater degree with its neighbours. Many wards in London and its neighbouring areas share origin and destination in journey to work activities.

Insert Figure 3 here

\section{CONCLUSIONS}

This paper defines fuzzy residential areas, fuzzy workplace areas and fuzzy travel-towork areas by a posterior analysis to conventional TTWAs. The membership value of a ward in a TTWA as a fuzzy residential area is defined as the proportion of the number of commuters who originate from the area to work in the ward to the total number of commuters originating from all wards including the ward itself to the ward. The membership of a ward in a TTWA as a fuzzy workplace area is defined as the proportion of the number of commuters from the ward who travel to work in the area to the total number of commuters originating from all wards to the area. The membership of a ward 
in a TTWA as a fuzzy TTWA is defined as the arithmetic average of memberships to the area as a residential place and a workplace.

Fuzzy count, an extension of the simple count of wards inside the TTWA, provides a more realistic and accurate size of a fuzzy TTWA. Size of a fuzzy TTWA can also be defined in terms of working population, and land area. Overlap between TTWAs can be measured using absolute and relative overlap indices. A novel method in cartographic representation of fuzzy regions is developed.

There are some potential applications of fuzzy membership values. For example, fuzzy membership values may be useful in assessing whether a TTWA is well defined. Although the criteria of constructing Travel-to-Work Areas are mainly based on the objective function that measures overall self-containment and population size, ideally each constituent zone should also have the largest membership value in the TTWA to which it is assigned. Calculation of membership values will reveal those wards which are mis-allocated to the 'wrong' TTWA and as a result, a fine tuning can be performed to move those wards to the TTWA in which they have the largest membership values, subject to population and self-containment constraints.

The memberships are also very useful to reveal the geographical variation of commuting patterns. It can be revealed that in the central areas of TTWAs there is usually a job focus area where people tend to have very strong association with the areas. Wards locating at the border areas of a TTWA usually have lower memberships in the area, highlighting the distance decay effect in commuting behaviour. The membership values can also be used 
to identify those wards which have ambiguous relationships with more than one TTWA. The disclosure of ambiguous wards in terms of connection with TTWAs enhances our insights on the complicated nature of commuting and local labour markets. This is in line with the spirit of the definition of urban areas in France, where areas showing no dominant link to a certain urban area but multiple links to different urban areas are grouped as a distinct category. However, the membership values provide information on degree of belongingness of constituent zones to a Travel to Work Area while the definition of multipolarised municipalities does not offer this to urban areas.

The absolute overlap index and relative overlap index provide alternatives in quantifying the commuting link between two areas. Potentially the overlap index may assist in construction of TTWAs as a measure of commuting link between areas. Since two TTWAs with a high overlap index have a strong connection with each other, the employment change in one TTWA may also affect the employment situation in the other TTWA.

Introduction of fuzzy logic to functional region construction is useful and the derived fuzzy measures may shed light on our understanding of commuting phenomena and the geography of local labour markets. The methodology used in examination of fuzziness of TTWAs may be helpful in developing a fuzzy approach to analyse other functional regions.

Acknowledgements - The 1991 census data were made available through the ESRC funded Centre for Interaction Data Services. The 1991 Travel-to-Work Areas and ward boundaries were made available through UKBORDERS funded by ESRC/JISC. All these 
geographical data and census data are crown copyright. I am grateful to Robin Flowerdew who provided very useful comments and proof-read the paper. This paper has also been benefited from the comments of three anonymous referees. Any remaining errors are my own.

\title{
REFERENCES
}

\begin{abstract}
ADAMS J., GREIG M. and MCQUAID R. (2000) Mismatch unemployment and local labour market efficiency: the role of employer and vacancy characteristics, Environment and Planning A 32, 1841-1856.
\end{abstract}

\begin{abstract}
ADAMS J., GREIG M. and MCQUAID R. (2001) Are spatially focused initiatives in current economic inclusion policies well founded? Local Economy. 16, 236-248.
\end{abstract}

\begin{abstract}
ANDERSEN, A.K. (2002) Are commuting areas relevant for the delimitation of administrative regions in Denmark? Regional Studies, 36(8), 833-844.
\end{abstract}

\begin{abstract}
ATKINS D., CHAMPION T., COOMBES M.G., DORLING D. and WOODWARD R. (1996) Urban trends in England: latest evidence from the 1991 Census. HMSO, London
\end{abstract}
BALL R. M. (1980) The use and definition of Travel-to-Work areas in Great Britain: some problems, Regional Studies, 14, 125-139.


BERRY B. J. L. and GILLARD Q. (1978) The Changing Shape of Metropolitan America: Commuting Patterns, Urban Fields and Decentralization Processes, 19601970. Ballinger, Cambridge, Massachusetts.

CASADO-DÍAZ, J.M. (2000). Local labour market areas in Spain: A case study. Regional Studies, 34, 843-856.

CATTAN N (2001) Functional regions: a summary of definitions and usage in OECD countries, OECD (DT/TDPC/TI(2001-6)), Paris

\author{
COLE K, FROST M, and THOMAS F. (2002) Workplace data from the census, in \\ REES, P. MARTIN, D. and WILLIAMSON P. (eds) The Census Data System, pp.269- \\ 280, Wiley, Chichester
}

COOMBES M. G. (2000) Defining locality boundaries with synthetic data, Environment and Planning A 32, 1499-1518.

COOMBES M. G. (2002) Travel-to-work areas and the 2001 census, Report to Office for National Statistics, University of Newcastle

COOMBES M. G. and OPENSHAW S. (1982) The use and definition of travel-to-work areas in Great Britain: some comments, Regional Studies 16, 141-149. 
COOMBES M.G., GREEN A. E. and OPENSHAW S. (1986) An efficient algorithm to generate official statistical reporting areas: the case of the 1984 Travel-to-Work Areas revision in Britain, Journal of the Operational Research Society 37, 943-953.

COUCLELIS, H. (1996) Towards an operational typology of geographic entities with illdefined boundaries. in BURROUGH P. A. and FRANK A. U., (eds) Geographic Objects with Indeterminate Boundaries, pp. 45-56. Taylor and Francis, London.

FENG Z. and FLOWERDEW R. (1998) Fuzzy geodemographics: a contribution from fuzzy clustering methods. in CARVER S. (ed) Innovations in GIS'5. pp.119-127, Taylor and Francis, London

FIELDHOUSE E.A. and GOULD M.I. (1998) Ethnic minority unemployment and local labour market conditions in Great Britain, Environment \& Planning A 30, 833-853.

GALE S., (1976) A resolution of the regionalization problem and its implications for political geography and social justice, Geografiska Annaler 58-B, 1-16

GERARD, R. (1958). Commuting and the labour market area. Journal of Regional Science, 1, 124-130

GREEN A.E. (1997) Alternative Approaches to Defining Local Labour Markets for Urban and Regional Policy, in TUROK I. (ed) Travel-to-Work Areas and the Measurement of Unemployment. Conference proceedings, Edinburgh 
GREEN A.E., HOGARTH T. and SHACKLETON R. (1999) Long distance living-dual location households. The Policy Press, London

GRIPAIOS P.A. and WISEMAN N. (1999) Explaining Differences in Unemployment between British Travel-to-Work Areas: The Role of Public Sector Employment, Journal of Interdisciplinary Economics 10, 51-58.

HARRIS T. R., STODDARD, S.W. and BEZDEK J.C. (1993) Application of fuzzy set clustering for regional typologies, Growth and Change 24, 155-165.

HASLUCK C (1983) The economic analysis of urban labour markets, Journal of Industrial Affairs 10, 25-31.

HATTERSLEY L. and CREESER R. (1995) Longitudinal Study 1971-1991, History, organization and quality of data. OPCS Series DS 15, HMSO, London

HATZICHRISTOS, T. (2004) Delineation of demographic regions with GIS and computational intelligence, Environment and Planning B 31, 39-49

HEIKKILA E. J., SHEN T. Y. and YANG K. Z. (2003) Fuzzy urban sets: theory and application to desakota regions in China, Environment and Planning B 30, 239-254 
LE JEANNIC T., (1997) Trente ans de periurbanisation: extension et dilution des villes, Economie et Statistiques, 307, 21-41

MCQUAID R.W. and GREIG M. (2001) A model of the commuting range of unemployed job seekers, in PITFIELD D. (ed) Transport Planning, Logistics and Spatial Mismatch: a Regional Science Perspective. pp.152-168, Pion, London

NEWELL J.O. and PERRY M. (2003) Functional labour markets revealed by travel to work data 1991 and 2001, mimeo, Monitoring and Evaluation Research Associates PO Box 2445, Wellington NZ and Labour Market Policy Group, Department of Labour

O'DONOGHUE D. (2000) Some evidence for the convergence of employment structures in the British urban system 1978 to 1991 , Regional Studies 34, 159-168.

OFFICE FOR NATIONAL STATISTICS (ONS) and COOMBES M. G. (1998) 1991based Travel-to-Work Areas, Office for National Statistics, London

PLANE D. (1981) The geography of urban commuting fields: some empirical evidence from New England, Professional Geographer 33, 182-188.

PLANE D. (1998) Fuzzy set migration regions, Geographical \& Environmental Modelling 2, 141-162. 
PAPPS K. L. and NEWELL, J. O. (2002) Identifying functional labour Market Areas in New Zealand: a reconnaissance study using travel-to-work data, working paper, no.443, Institute for the Study of Labor

ROLLAND-MAY C. (1984) Notes sur les espaces geographiques flous, Bulletin de l'Association de géographes français (BAGF) 502, 159-164.

SFORZI F., OPENSHAW S. and WYMER C. (1997) Le procedura di identificazione dei sistemi locali del lavoro, [The procedure to identify local labour market area], in Sforzi, (ed) I sistemi locali del lavoro 1991, pp.235-242 ISTAT, Rome

SMART M. W. (1974) Labour market areas: uses and definitions, Progress in Planning 2, 239-353.

VANCE, J.E. (1960). Labour shed, employment field and dynamic analysis in urban geography. Economic Geography, 36, 189-220

WARD C. and DALE A. (1992) Geographical variation in female labour force participation: an application of multilevel modeling, Regional Studies 26, 243-255.

WATTS M. (2004) Local labour markets in New South Wales: fact or fiction? Working paper No. 04-12, Centre of Full Employment and Equity, The University of Newcastle, Callaghan NSW 2308, Australia 
WEBSTER D. (1997) Travel to Work Areas and local unemployment statistics: a Glasgow view in TUROK I. (ed) Travel to Work Areas and the Measurement of Unemployment, Conference proceedings, Edinburgh

ZADEH L. A. (1965) Fuzzy sets, Information and Control 8, 338-353. 
Table 1 Top 20 TTWAs with the highest proportion of wards that have low memberships $(<0.5)$ in their allocated TTWAs

\begin{tabular}{lcc}
\hline TTWA & $\begin{array}{c}\text { Number of } \\
\text { wards }\end{array}$ & Percentage \\
\hline Keswick & 4 & 50.0 \\
Dartmouth & 5 & 40.0 \\
Leek & 13 & 38.5 \\
Launceston & 11 & 27.3 \\
Matlock & 22 & 22.7 \\
Gainsborough & 9 & 22.2 \\
Barnard Castle & 14 & 21.4 \\
Loughborough & 24 & 20.8 \\
Haltwhistle & 5 & 20.0 \\
Weston-super-Mare & 15 & 20.0 \\
Okehampton & 16 & 18.8 \\
Rugby & 23 & 17.4 \\
Retford & 12 & 16.7 \\
Ilfracombe & 7 & 14.2 \\
Malton & 7 & 14.3 \\
Malvern & 21 & 14.3 \\
Liskeard & 15 & 13.3 \\
Cirencester & 24 & 12.5 \\
Pickering & 8 & 12.5 \\
Redruth and Camborne & 8 & 12.5 \\
\hline \multicolumn{1}{c}{ Source: Special Workplace Statistics Set C, 1991}
\end{tabular}

Source: Special Workplace Statistics Set C, 1991 
Table 2 Top 20 TTWAs with the largest fuzzy count

\begin{tabular}{lcc}
\hline TTWA & $\begin{array}{c}\text { Number of } \\
\text { wards }\end{array}$ & Fuzzy count \\
\hline London & 945 & 1022.3 \\
Manchester & 205 & 216.0 \\
Slough and Woking & 195 & 196.8 \\
Birmingham & 163 & 178.1 \\
Tyneside & 149 & 153.6 \\
Bristol & 130 & 136.4 \\
Nottingham & 130 & 129.8 \\
Maidstone and North Kent & 126 & 123.7 \\
Leicester & 116 & 114.6 \\
Oxford & 104 & 102.3 \\
Liverpool & 100 & 101.9 \\
Norwich & 98 & 101.8 \\
Guildford and Aldershot & 102 & 97.8 \\
Crawley & 101 & 94.9 \\
Southampton and Winchester & 89 & 90.7 \\
Reading & 88 & 90.1 \\
Middlesbrough and Stockton & 86 & 90.1 \\
Southend & 92 & 89.4 \\
Aylesbury and Wycombe & 96 & 87.5 \\
Sunderland and Durham & 76 & 79.7 \\
\hline
\end{tabular}

Source: Special Workplace Statistics Set C, 1991 
Table 3 Top 20 TTWAs with the largest working population (10\% sample)

\begin{tabular}{lc}
\hline TTWA & Workers \\
\hline London & 295327 \\
Manchester & 77291 \\
Birmingham & 66894 \\
Slough and Woking & 52971 \\
Tyneside & 34556 \\
Liverpool & 32773 \\
Bristol & 29102 \\
Leeds & 28830 \\
Sheffield and Rotherham & 28812 \\
Nottingham & 26795 \\
Leicester & 24386 \\
Southampton and Winchester & 21170 \\
Reading & 20539 \\
Maidstone and North Kent & 20187 \\
Coventry & 19732 \\
Dudley and Sandwell & 19206 \\
Southend & 18918 \\
Wolverhampton and Walsall & 18918 \\
Bradford & 18556 \\
Crawley & 17678 \\
\hline Source: Special Workplace Statistics Set C, 1991,
\end{tabular}

30

31

32

33

34

35

36

37

38

39

40

41

42

43

44

45

46

47

48

49

50

51

52

53

54

55

56

57

58

59

60 
Table 4 Top 20 TTWAs with the largest fuzzy area (square kilometre)

\begin{tabular}{lcc}
\hline TTWA & Area & Fuzzy area \\
\hline London & 2951.3 & 4714.4 \\
Birmingham & 1393.7 & 1776.5 \\
Manchester & 1525.3 & 1751.7 \\
Norwich & 1520.3 & 1726.9 \\
Oxford & 1670.0 & 1704.3 \\
Tyneside & 1162.9 & 1576.0 \\
Hexham & 1627.5 & 1523.5 \\
Cambridge & 1470.1 & 1497.6 \\
Carlisle & 1397.6 & 1493.6 \\
Shrewsbury & 1322.2 & 1344.3 \\
Hereford & 1328.8 & 1296.0 \\
Exeter & 1097.7 & 1295.9 \\
Plymouth & 1003.1 & 1248.5 \\
Southampton and Winchester & 1219.1 & 1241.3 \\
Maidstone and North Kent & 1318.0 & 1238.4 \\
Leicester & 1258.7 & 1237.1 \\
Bristol & 1044.4 & 1206.7 \\
Hull & 1086.9 & 1200.9 \\
Crawley & 1360.4 & 1190.5 \\
Harrogate and Ripon & 1265.7 & 1147.8 \\
\hline
\end{tabular}


Table 5 Top 20 TTWA pairs by absolute overlap index

\begin{tabular}{llc}
\hline TTWA & TTWA & $\begin{array}{c}\text { Absolute } \\
\text { overlap }\end{array}$ \\
\hline London (1022.3) & Slough and Woking (196.8) & 67.6 \\
London (1022.3) & Southend (89.4) & 30.2 \\
London (1022.3) & Maidstone and North Kent (123.8) & 26.2 \\
London (1022.3) & Crawley (94.9) & 22.7 \\
London (1022.3) & Harlow (68.0) & 22.1 \\
Sunderland and Durham (79.8) & Tyneside (153.6) & 19.8 \\
Guildford and Aldershot (97.8) & Slough and Woking (196.8) & 15.0 \\
Birmingham (178.1) & Wolverhampton and Walsall (61.7) & 14.7 \\
Reading (90.2) & Slough and Woking (196.8) & 14.5 \\
London (1022.3) & Aylesbury and Wycombe (87.6) & 14.2 \\
Bournemouth (51.4) & Poole (39.9) & 13.8 \\
London (1022.3) & Colchester (74.7) & 13.7 \\
London (1022.3) & Stevenage (66.8) & 13.4 \\
Birmingham (178.1) & Dudley and Sandwell (47.7) & 12.9 \\
Morpeth and Ashington (38.5) & Tyneside (153.6) & 12.8 \\
London (1022.3) & Tunbridge Wells (54.2) & 12.2 \\
London (1022.3) & Luton (49.8) & 11.6 \\
Derby (52.1) & Nottingham (129.8) & 10.8 \\
Brighton (64.9) & Crawley (94.9) & 10.6 \\
Slough and Woking (196.8) & Aylesbury and Wycombe (87.6) & 10.3 \\
\hline Not Fuzzy coug a TWA is in brat.
\end{tabular}

Note: Fuzzy count of a TTWA is in bracket.

Source: Special Workplace Statistics Set C, 1991 
Table 6 Top 20 TTWA pairs by relative overlap index

\begin{tabular}{llc}
\hline TTWA & TTWA & $\begin{array}{r}\text { Relative } \\
\text { overlap }\end{array}$ \\
\hline Bournemouth (51.4) & Poole (39.9) & 0.205 \\
Burnley (24.4) & Nelson and Colne (18.5) & 0.191 \\
Paignton and Totnes (13.9) & Torquay (8.5) & 0.174 \\
Redruth and Camborne (9.5) & Truro (15.3) & 0.169 \\
Newton Abbot (17.5) & Torquay (8.5) & 0.157 \\
Cheltenham (37.6) & Gloucester (36.4) & 0.156 \\
Barnstaple (19.2) & Bideford (16.7) & 0.146 \\
Malton (6.8) & Pickering (7.0) & 0.137 \\
Bude (5.2) & Holsworthy (5.7) & 0.134 \\
Falmouth (8.4) & Truro (15.3) & 0.133 \\
Newton Abbot (17.5) & Paignton and Totnes (13.9) & 0.131 \\
Dudley and Sandwell (47.7) & Wolverhampton and Walsall (61.7) & 0.130 \\
Appleby (9.0) & Penrith (15.5) & 0.128 \\
Malvern (18.2) & Worcester (34.6) & 0.124 \\
Whitehaven (25.3) & Workington (26.1) & 0.124 \\
Barnstaple (19.2) & Ilfracombe (6.4) & 0.122 \\
Kendal (24.8) & Windermere (9.4) & 0.120 \\
Camelford (4.4) & Wadebridge and Bodmin (10.5) & 0.111 \\
Canterbury (33.0) & Dover (25.3) & 0.108 \\
Sunderland and Durham (79.8) & Tyneside (153.6) & 0.105 \\
\hline Note: Fuzzy c0int of a TWA & brket.
\end{tabular}

Note: Fuzzy count of a TTWA is in bracket.

Source: Special Workplace Statistics Set C, 1991 


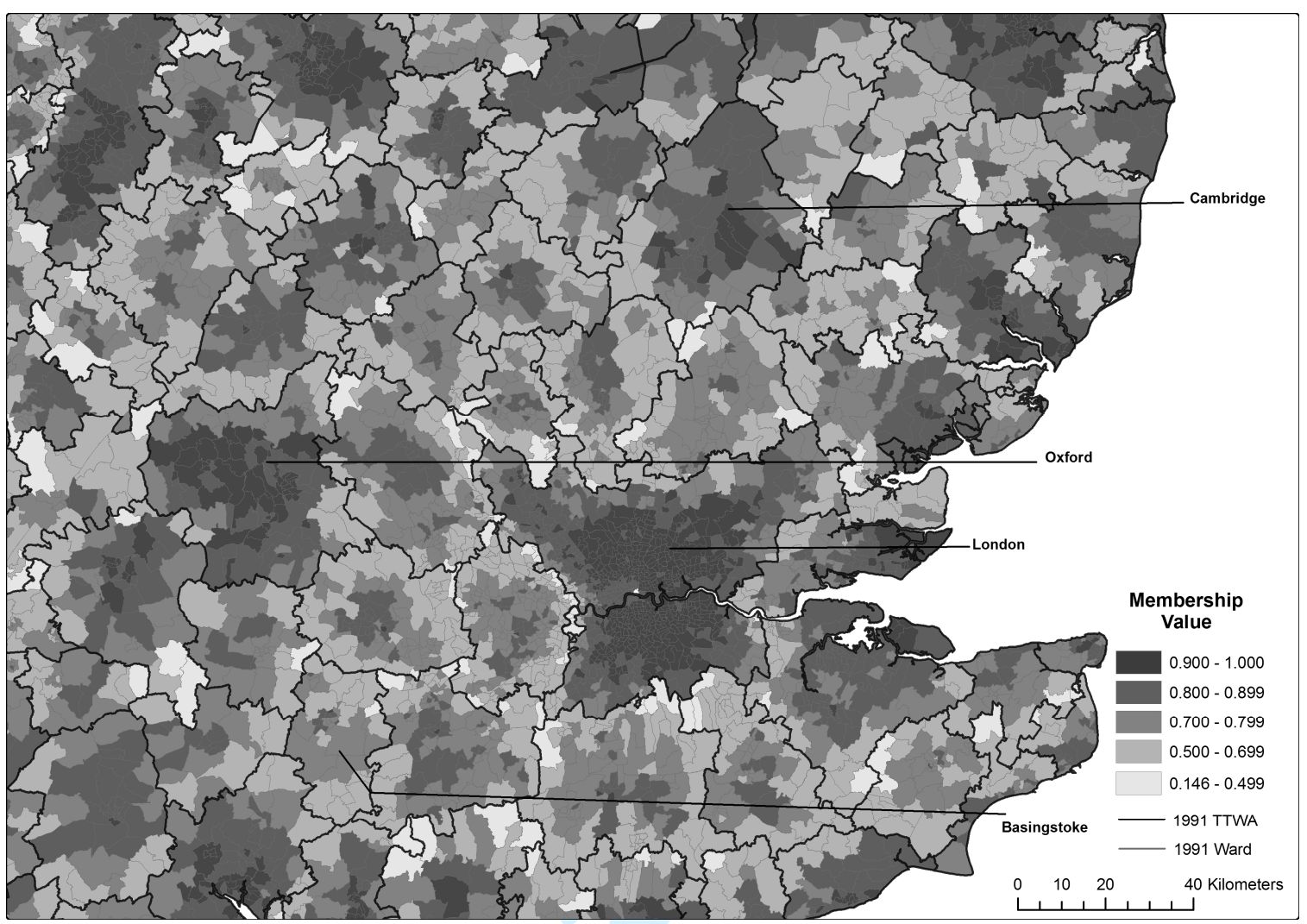

Fig. 1 Membership values of wards in the TTWAs to which they were allocated, London and surrounding areas 


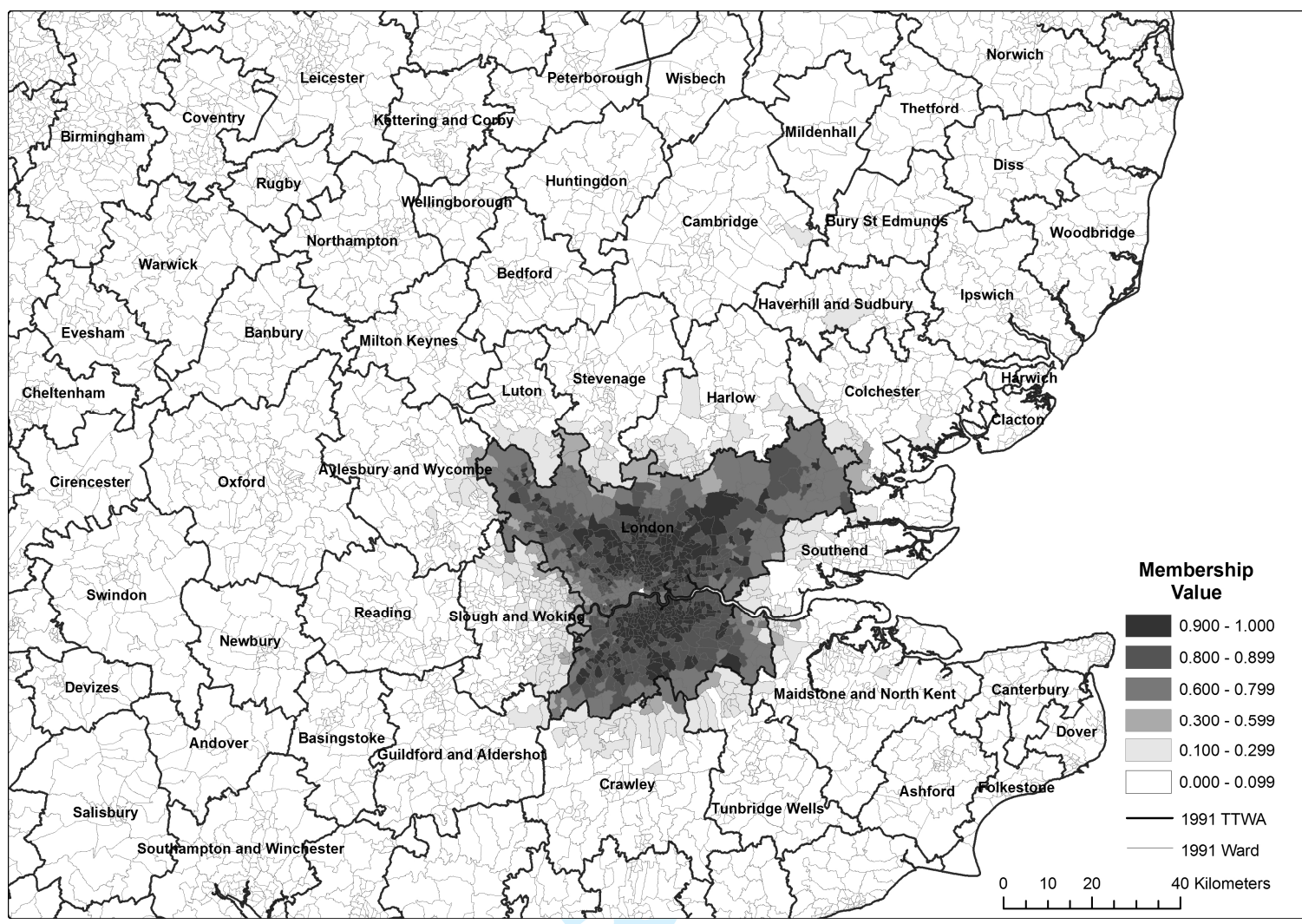

(a)

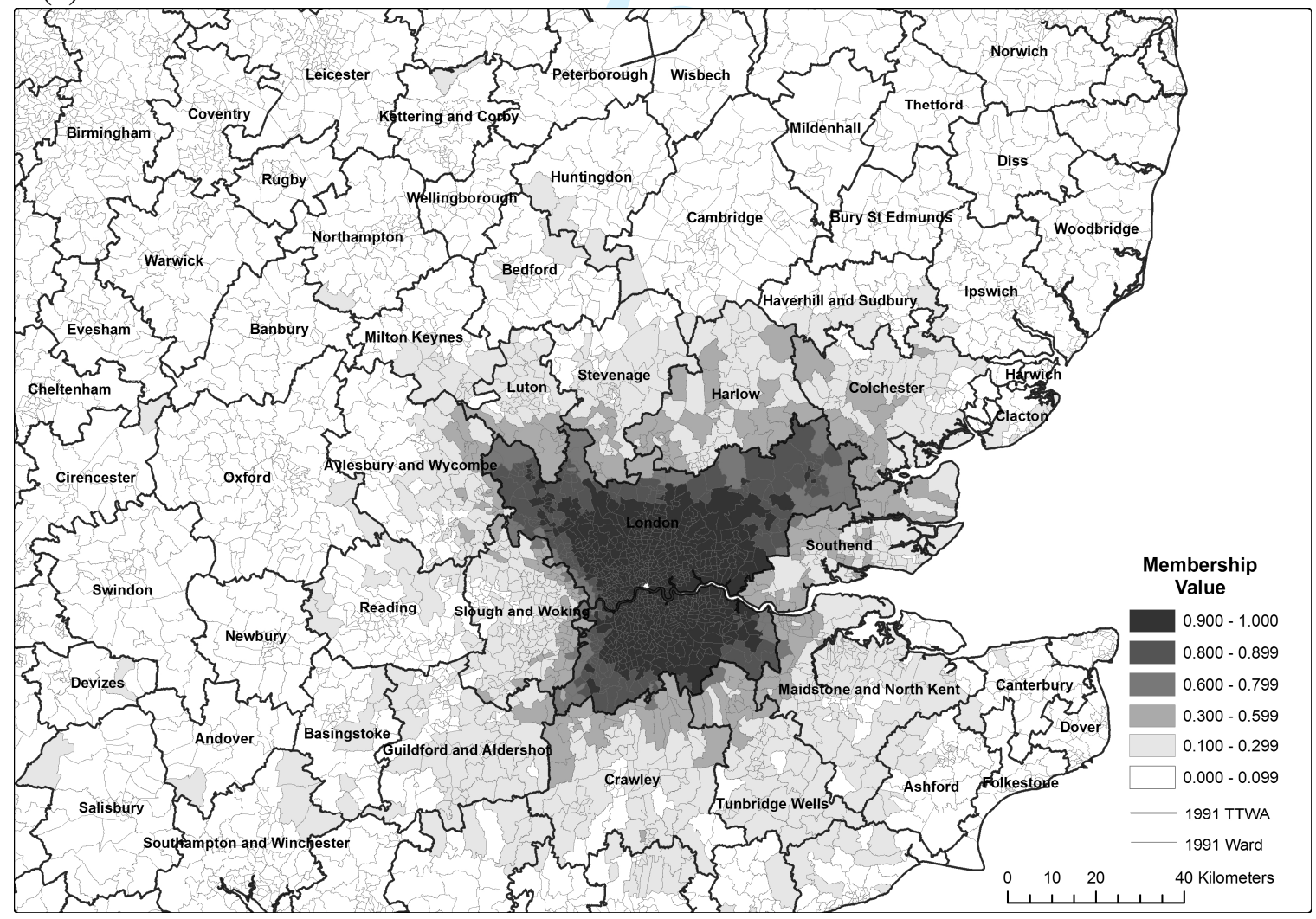

(b) 


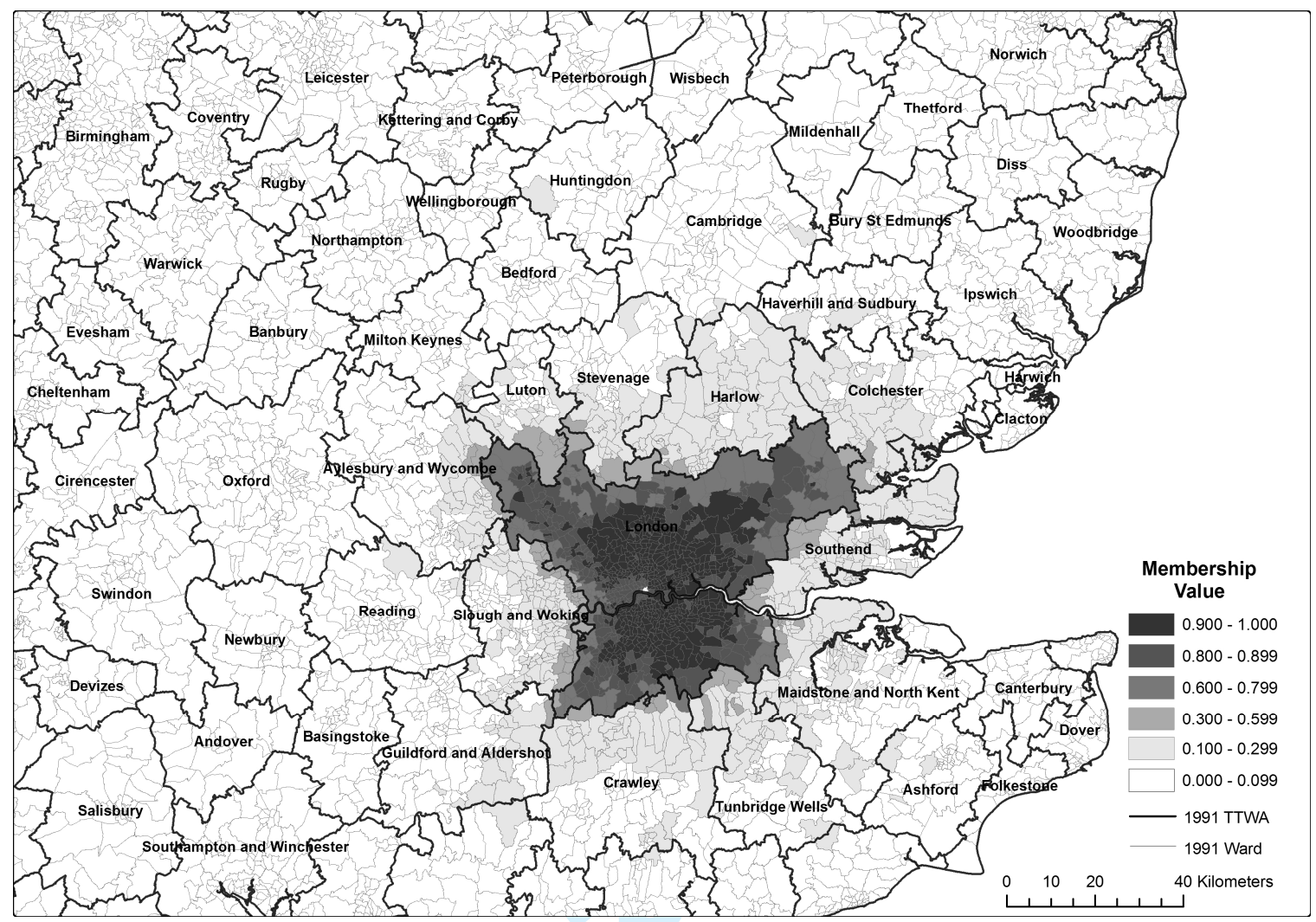

(c)

Fig. 2 Membership values of wards in London as a residential area (a), workplace area (b) and TTWA (c) 


\section{Overlap Index}
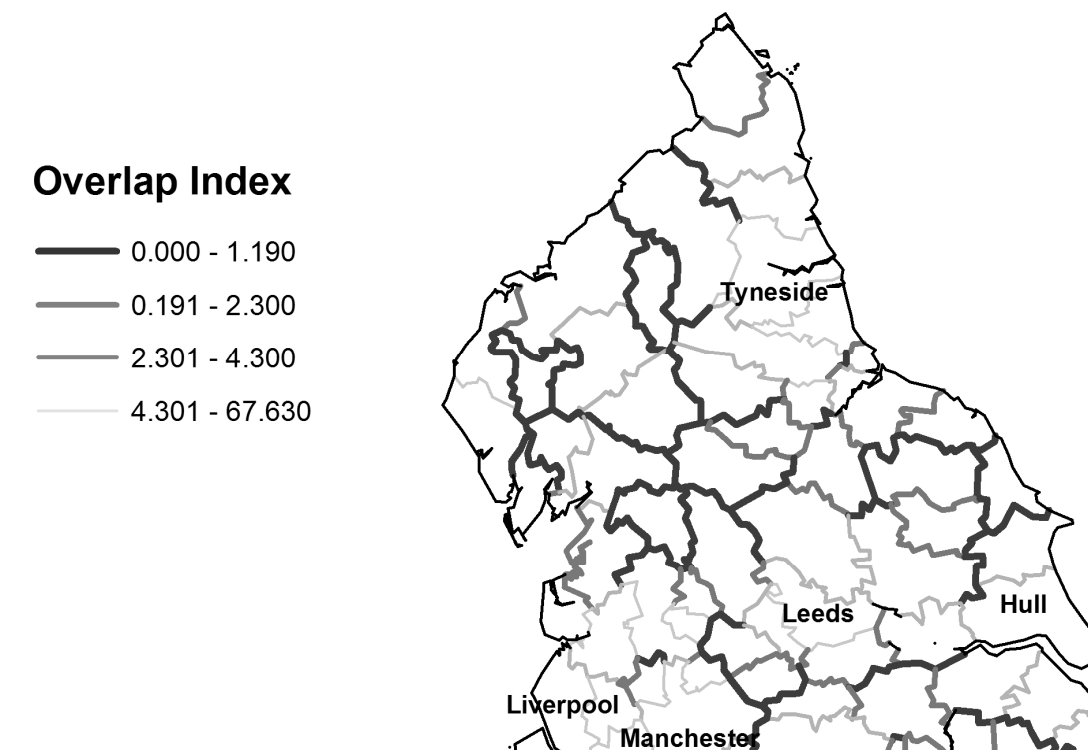